\title{
Nanofluids Thin Film Flow of Reiner-Philippoff Fluid over an Unstable Stretching Surface with Brownian Motion and Thermophoresis Effects
}

\author{
Asad Ullah ${ }^{1,2, *}$, Ebraheem O. Alzahrani ${ }^{3}$, Zahir Shah ${ }^{1}\left(\mathbb{D}\right.$, Muhammad Ayaz $^{1}$ and Saeed Islam ${ }^{1}$ (I) \\ 1 Department of Mathematics, Abdul Wali Khan University, Mardan 23200, Khyber Pakhtunkhwa, Pakistan; \\ Zahir1987@yahoo.com (Z.S.); mayazmath@awkum.edu.pk (M.A.); saeedislam@awkum.edu.pk (S.I.) \\ 2 Department of Mathematics, Kohat University of Science \& Technology, \\ Kohat 26000, Khyber Pakhtunkhwa, Pakistan \\ 3 Department of Mathematics, Faculty of Science, King Abdulaziz University, P. O. Box 80203, \\ Jeddah 21589, Saudi Arabia; eoalzahrani@kau.edu.sa \\ * Correspondence: asad.ullah@kust.edu.pk; Tel.: +92-300-667-7148
}

Received: 22 November 2018; Accepted: 27 December 2018; Published: 30 December 2018

\begin{abstract}
The current investigation is carried out on the thin film flow of Reiner-Philippoff fluid of boundary-layer type. We have analyzed the flow of thin films of Reiner-Philippoff fluid in the changeable heat transmission and radiation over a time-dependent stretching sheet in $2 \mathrm{D}$. The time-dependent governing equations of Reiner-Philippoff fluid model are simplified with the help of transformation of similarity variables. To investigate the behavior of the Reiner-Philippoff fluid with variable stretching surface for different physical effects, we considered thermophoresis and Brownian motion parameters in the flow. The Homotopy Analysis Method is implemented in the reduced model to achieve a solution of the original problem. A numerical convergence of the implemented method is also analyzed. The behavior of temperature, velocity, and concentration profiles have been investigated with the variation of skin friction, Nusselt number, and Sherwood number. A comparative graphical survey is presented for the velocity gradient, under different parameters. An analytical analysis is presented for the time-dependent parameter over thin film flow. The results we obtained are better than the previously available results. For the survey, the physical representation of the embedded parameters, like, $\beta$ depends on the stretching parameter $\zeta$, and the Reiner-Philippoff fluid parameter $\epsilon$ are discussed in detail and plotted graphically. Prandtl number $\mathrm{Pr}$, Brownian motion parameter $\mathrm{Nb}$, thermophoretic number $\mathrm{N} t$, and Schmidt number $\mathrm{Sc}$ are presented by graphs and discussed in detail.
\end{abstract}

Keywords: Reiner-Phillipoff fluid; thin film; time-dependent; thermal radiation; homotopy analysis method (HAM)

\section{Introduction:}

In the last few decades, scientists have given great attention to thin film flow. The basic idea behind such an important concept is the applications and mechanism of thin film flow. Thin films are ubiquitous in nature and their mechanism is important to understand, because it has a wide range of practical uses. The traditional theory of Newtonian fluids is mainly focused on the linear relationship between stress and strain tensor or on their rates. Newtonian fluids are hardly pointing towards the doctrine of linear relation between the stress and strain tensor. In the same way, fluids that do not agree with the linear distribution between the stress and strain tensor are known as non-Newtonian fluids. There are two main classes of non-Newtonian fluids, visco-inelastic and visco-elastic fluids. The subsequent has great importance due its dual nature. Visco-elastic fluids, due to their viscosity, show 
an elastic behavior up to some degree. In such fluids, energy is stored in the form of strain energy. One cannot ignore the strain in these types of fluids, because it is responsible to recover the original state. These fluids came under the definition of Newtonian fluids, when there is a first order derivative of all the tensor formed from the velocity field, while fluids having higher order derivative tensors present come under the definition of non-Newtonian fluids. Some of these fluids are second order, third order, and fourth order fluids. Third order liquid, which is due to its sequential nonlinear constraints, has a variety of applications.

The study of non-Newtonian fluids from a theoretical point of view is too complicated and we need a mathematical relation to briefly illuminate the relation between shear stress and the shear rate. Therefore, a variety of non-linear relations have been suggested for the study of these fluids. As a consequence, to deliberate such a categorizing demeanor, various models have been initiated and discussed in [1]. Non-Newtonian fluids are not so simple that a single mathematical relation can explain the whole scenario. Therefore, for this purpose, several models have been initiated and developed to briefly explain the nature of such fluids. Among all, Ellis fluid model, Sisko fluid model, the Carreau viscosity model, Ostwald-de Waele model, the cross-viscosity model, Carreau-Yasuda model, Powell-Eyring model, and Reiner-Philippoff fluid model are the most important models in explaining the nature of such fluids. These models have interesting properties in their own, in which the Ostwald-de Waele model is considered to be the basic model, normally known as the Power law model. The subsequent of all models discussed here is a time-independent three-parameter model, behaving like non-Newtonian fluids under intermediate shear rates and Newtonian fluids at extreme shear rates. Consequently, due to their dual nature, Reiner-Philippoff fluid has many applications in engineering sciences and other technologies.

A variety of fluids are available in nature, in which nanofluids are the most interesting fluids, due to their variety of applications. The most commonly uses of nanofluids are metal oxides, oxide ceramics and chemically stable metals, like Alumina, Silica, Zirconia, Titania, aluminum oxide, copper oxide, gold, copper and various forms of allotropes of carbon and metal carbides. Water, oils, polymeric solutions, lubricants, bio-fluids, and glycols are normally used as base fluids. Nanofluids are two-phased mixtures designed by spreading nanometer-sized particles, in which base fluid size ranging up to $100 \mathrm{~nm}$. Nanoparticles play a key part in heat transfer analysis. On the other hand, applications of liquid film flow grow day by day. The most common uses of these flows are in heat exchange processes, techniques of coating, industrial and distillation processes, and many more. The applied usage of the liquid film flow is a fascinating interaction amongst fluid mechanics, structural mechanics, and technology. Some of the practical usages are polymer and metal extrusion, foodstuff processing, plastic sheets depiction, casting and fluidization of the reactor.

In the assessment of these applications, researchers have taken a keen interest in the study of liquid film flow on unstable surfaces. Stretching sheets at the beginning were treated as linear surfaces. Such a phenomenon encountered in many industrial processes, like, in cooling, extraction of polymer sheets and plastic sheets, etc. In these industrial processes the stretching sheet contacts with the fluid both mechanically and thermally. Sakiadis [2] work is considered to be the pioneering work in the study of boundary-layer flow over non-stationary and rigid surfaces. But in polymer industries stretching sheet play a key role, which is explained by Crane [3] in his famous work. After the work of Crane on stretching sheet and its numerous applications in the polymer industry, researchers have shown great interest in it. Stretching sheet problems have been investigated by different researchers under different physical parameters with their variations, like viscosity and thermal conductivity, magnetic and electric fields (MHD), thermal radiation, viscous dissipation, and chemical reactions etc.

Similar to the variations in the parameters for the stretching sheet, the same phenomenon of stretching problem is studied for different geometries and is developed from time to time. Siddiqui et al. [4,5] investigated non-Newtonian fluids on a moving built with a sloping plane in one direction for thin film flow. Tawade et al. [6] studied the effect of magnetic field upon a thin fluid stream passes over a temperamental stretching sheet with heat. They used two different numerical 
approaches, Newton-Raphson and RK-Felberg. They briefly explained and provided a detailed survey of different physical parameters.

Beside all these, the implemented techniques are not to be ignored. In literature, the boundarylayer equations obtained for stretching flow are solved by different approaches. Among all, numerical and perturbation approaches have been adopted and applied by many researchers successfully. In practice, numerical techniques are too difficult to apply due to the high non-linearity of the model equations, whereas perturbation techniques are not always applicable. Perturbation techniques need a small or large parameter to be presented in the equation, which is not always available to us. To overcome this situation, some new techniques were developed and implemented by the researchers successfully. Sajid and Hayat [7] used HAM and HPM to thin film flow of Sisko fluid and Oldroyed-6 constant. The effect of thermal radiations of blending convection stream over a steeping surface in a permeable channel is studied by Bakier [8]. Nargis and Tahir [9] have given a more detailed survey of grade third fluid on a moving belt in the direction of a slanted plane. Stretching problem in permeable medium with thermal effects of a slanted plate is investigated by Moradi et al. [10]. Chaudhary et al. [11] re-examined thermal radiation impacts of liquid on exponentially extending surfaces. Eldabe et al. [12] examined convection, radiation, and synthetic effects of MHD visco-elastic fluid flow in a permeable channel on a horizontal stretching sheet. Das [13] has investigated some important properties of thermal radiation and thermophoresis of MHD blended convective flow. Recently, Hsiao [14] has examined the heat and mass trasfer effects of Maxwell fluid. MHD flow of different models, like Powell-Eyring nanofluid and other non-Newtonian fluids on stretching surfaces are briefly explained in [15-17]. Crane [3] for the first time studied the flow of gummy liquid in a stretched surface. The effect of heat exchange on an extending sheet for viscoelastic liquids is discussed by Dandapat [18]. Wang [19] for the first time studied finite liquid film on an unsteady stretching domain. The problem discussed by Wang [19] has discussed by Usha and Sridharan [20] with a survey on different parameters. For a heat transfer analysis of liquid film fluid, numerical results for different parameters were obtained by Liu and Andersson [21]. The repercussion in the thin liquid film on an unsteady stretching sheet due to the inner heat production was examined by Aziz et al. [22].

The thin liquid film flow of non-Newtonian fluids has a lot of practical features. Consequently, it becomes a common solute in engineering and other technologies. Andersson et al. [23,24] investigated the non-Newtonian thin liquid films at a time depending stretching sheet by taking the Power law model in consideration. After this pioneer investigation of Andersson, scientists have given more attention to stretching problems by using the Power law model, for more detail see $[25,26]$. Other models also came in discussion during this era. Megahed et al. [27] examined the thin liquid film flow of Casson liquid for viscous promulgation with slip velocity and the transmission of variable heat transition. The same scenario was discussed by Abolbashari et al. [28] for nano particles with the generation of entropy. Buongiorno's model for nano fluid thin film on a temperamental extending stretched sheet was recently investigated by Qasim et al. [29]. A steady flow of liquids through a porous medium is studied by Ariel [30]. Ariel got a high non-linear coupled boundary value problem for the geometry under consideration and applied numerical methods to obtain an appropriate solution. Sahoo et al. [31] investigated heat exchange analysis with a uniform oblique magnetic field for non-Newtonian fluids. They successfully applied finite difference and Broyden's methods for the concatenation of the field of the velocity. Aiyesimi et al. [32,33] examined the thin liquid film flow of an MHD grade third fluid and obtained some interesting results by using perturbation techniques with a brief survey impact of slip parameters and magnetic parameters. Third grade fluid and its approximate analytical solution by using OHAM for three different kinds of flow has discussed by Islam and Shah et al. [34,35]. Makinde [36] studied the same geometry with isothermal effects for hydro-dynamically third order liquid film flow. The approximate solution for velocity and temperature was obtained by a Hermitepade method. A brief discussion and explanation was given by Yao and Liu [37] of the second order fluid over flat plates for unsteady flows. Erdogan et al. [38] examined the properties of unsteady flow of the 
non-Newtonian fluids, with a brief description on Poiseuille, Couette, and generalized form of Couette flow. Abdulhameed et al. [39] successfully applied Laplace transformation, perturbation techniques, and separation of variable methods for the clarity of unsteady non-Newtonian fluids over an oscillating plate. Huan was the first to settle variational rules for nano thin film-lube [40] with the help of the method of semi-inverse [41-45]. Kapitza [46], Yih [47], Krishna and Lin [48], Anderson and Dahl [49], and Cheng et al. [50] considered thin film flow problems with distinct geometric expressions. As time passes, the thin film flow applications in engineering sciences increase day by day and as a result, the researchers extended the work to a new world. Recently, coating and fiber applications of thin film flow are described and discussed in [51-54]. The geometry and other physical constraints have fixed, but some impurities have been introduced to the study as discussed in [55,56], to improve and enhance the heat transfer analysis.

An interesting and remarkable behavior of time-dependent non-Newtonian fluid is its pseoudo-plasticity, which vanishes with the expansion of shear rate. Many models have initiated as discussed earlier in the investigation of the behavior of such fluids. Among all, in Reiner-Philippoff fluid model [57], researchers have shown great interest. In 1965, Kapr and Gupta [58] have studied Reiner-Philippoff fluid two-dimensional flow in a linear channel. Different approaches have been adopted with different geometrical aspects to discuss this famous model.

In 1994, Tsung-Yen [59] investigated the boundary-layer flow problems by using this model. The basic idea of boundary-layer theory was introduced by L. Prandlt in Heidelberg, Germany, in August 1904, at the third International Congress of Mathematicians. It is the region in the fluid flow, developing at large Reynolds numbers. This region is strongly affected by inertial forces and viscous forces. Boundary layer theory is very important and has a variety of dimensions and visual perception of interest, and has been studied for a long interval of time. In 2009, this model was investigated by Yam [60] for the boundary flow past a stretching wedge. During this era Patel and Timol [61] used the technique of similarity solution for three dimensional boundary layer type equations for non-Newtonian fluids. Ahmad [62] examined the Reiner-Phillippoff fluid flow based nano-liquids past a stretching sheet. Recently, Ahmad et al. [63] discussed the same model with the same geometry with shifting and thickness in the stretching sheet.

Discussion has shown that different problems arise due to varying geometry as well as the fluid behavior, and different approaches are adopted by the researchers to meet their needs. Most of the problems that arise are highly non-linear and it is a difficult job to handle such problems with the usual available techniques in literature. Nowadays, perturbation techniques $[64,65]$ are in the main stream for dealing with such problems. These methods work in the presence of small or large scale parameters. These parameters are not always available to us in applied sciences and we cannot apply these techniques to these types of problems. To deal with such problems, we use non-perturbative techniques like the "Lyapunov's artificial small parameter method" [66], the method of d-Expansion, and the adomians decomposition method (ADM) [67]. Various approaches have been adopted by researchers to find the solution to their problems. An exact solution in literature is very rare. This is because of the complexity of the geometry of the problem. That is why we often see numerical approaches to find the approximate solution. Among all, homotopy analysis method (HAM) [68-70] is the one by virtue of which we can find the approximate solution. In 1992, Liao [71] for the first time developed and implemented this method and found solution in the form of series in a single variable. Liao also discussed the convergence of this proposed method and found a rapid convergence. HAM has some interesting points of interest. Most importantly, this method is independent of whether a given non-linear problem contains any small or large parameters or not. In HAM, we can modify and control the region of convergence, where necessary, and is helpful in selecting distinct sets of base operations, which approximate a non-linear problem with less effort.

The goal of our current investigations is to obtain the thin liquid film flow of Reiner-Philippoff fluid over a stretching sheet with heat transfer and thermal radiations. Boundary-layer equations are obtained from the physical demonstrated geometry. Thermophoresis effects and Brownian motion 
are also encircled with different physical parameters. A similarity solution is obtained with the help of new variables, due to which a complicated model is transformed into simple coupled ordinary differential equations. An analytical approach is adopted for the solution of the reduced system. HAM is implemented with initial guess as required for the implementation of the technique, due to its fast convergence. With the variation of different physical parameters, the results are plotted, tabulated, and discussed in detail. The physical significance of Sherwood number and skin friction is presented by tables.

\section{Problem Formulation}

Consider an electrically conducting and time-dependent thin film flow of Reiner-Philippoff fluid over spreading sheet. The elastic sheet start moving from fixed slit. The coordinates oxyz are adjusted in such way that $o x$ and the plate are equal, and $o y$ is along the sheet. The origin is at rest in the direction of the $x$-axis, due to the two equal and opposite forces of the stretching sheet flow. We take the $x$-axis in the direction spreading sheet and has the stress velocity $U_{w}(x, t)=\gamma x(1-\zeta t)^{-1}$, where $\gamma$ and $\zeta$ represent any fix numbers, which are vertical to $y$-axis as shown in Figure 1.

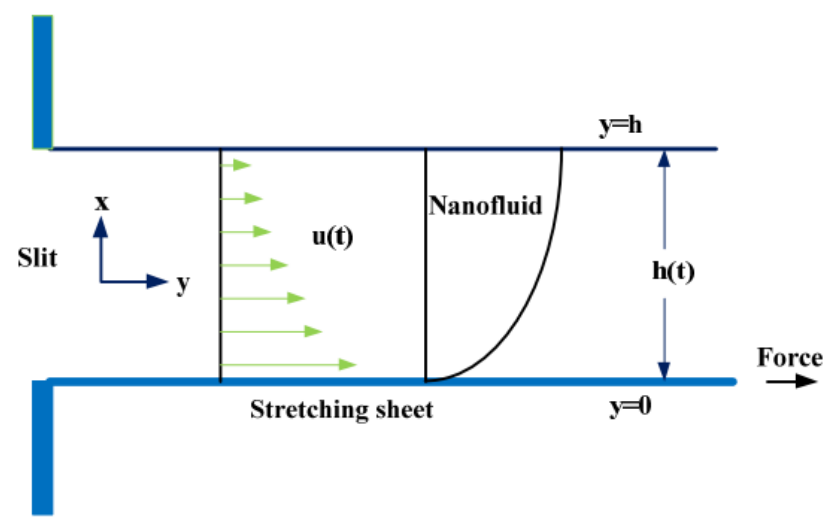

Figure 1. Geometry of the physical model.

The wall temperature $[72,73]$ of the liquid is

$$
T_{w}(x, t)=\left(\frac{\gamma x^{2}}{2(1-\zeta t)^{1.5} v_{f}}\right) T_{r}+T_{0}
$$

and the capacity of the nanoparticles is given by

$$
C_{w}(x, t)=\left(\frac{\gamma x^{2}}{2(1-\zeta t)^{1.5} v_{f}}\right) C_{r}+C_{0}
$$

where $v_{f}$ denotes the fluid kinematic viscosity, $T_{0}$ and $C_{0}$ denote the temperature of the slit and volume friction of the nanoparticles, while $T_{r}$ and $C_{r}$ represent the reference temperature and reference volume of the nanoparticles respectively. Assume that the effects of body forces are negligible in the field of flow. In light of the previous assumptions, the equation of continuity, the basic boundary governing equations, concentration, and heat transferring equations take the following forms.

The stress deformation behavior is well explained by Reiner-Philippoff in [74], and is considered one of the classical descriptions and is given by an implicit functional way:

$$
\tau_{i j}=\left[\mu_{0}+\frac{\mu_{\infty}-\mu_{0}}{\frac{1}{2 \tau_{0}^{2}}\left(\sum_{p=1}^{3} \Sigma_{q=1}^{3} \tau_{p q} \tau_{q p}\right)}\right] e_{i j}
$$


where the parameters $\mu_{0}, \mu_{\infty}$, and $\tau_{0}$ are greater than zero. This model gives interesting results due to its behavior, for large or small values of the model nearly agree with Newtonian fluids. Besides this, when the values of $\tau_{0}$ are in between the extremes the model agrees with non-Newtonian fluids. the form:

The Momentum equations for two dimensional flow together with the continuity equation takes

$$
\begin{gathered}
\frac{\partial \tilde{u}}{\partial x}+\frac{\partial \tilde{v}}{\partial y}=0 \\
\rho\left(\frac{\partial \tilde{u}}{\partial t}+\tilde{u} \frac{\partial \tilde{u}}{\partial x}+\tilde{v} \frac{\partial \tilde{u}}{\partial y}\right)+\frac{\partial p}{\partial x}=\frac{\partial \tau_{x x}}{\partial x}+\frac{\partial \tau_{x y}}{\partial y} \\
\rho\left(\frac{\partial \tilde{v}}{\partial t}+\tilde{u} \frac{\partial \tilde{v}}{\partial x}+\tilde{v} \frac{\partial \tilde{v}}{\partial y}\right)+\frac{\partial p}{\partial y}=\frac{\partial \tau_{x y}}{\partial x}+\frac{\partial \tau_{y y}}{\partial y}
\end{gathered}
$$

The components of stress, presented above, are difficult to present in a closed single explicit format. For this purpose, we assume a small $\tau_{0}$ such that its higher powers greater than three vanishes. The stress components take the form:

$$
\tau_{x y}=\tau_{x x}^{0}+\tau_{0}^{2} \tau_{x x}^{\prime}
$$

with the constitutive relations defined by

$$
\tau_{x x}^{0}=\mu_{0}\left(2 \frac{\partial \tilde{u}}{\partial x}\right), \tau_{y y}^{0}=\mu_{0}\left(2 \frac{\partial \tilde{v}}{\partial y}\right), \tau_{x y}^{0}=\mu_{0}\left(\frac{\partial \tilde{u}}{\partial y}+\frac{\partial \tilde{v}}{\partial x}\right)
$$

where $\tau_{x x}^{0}$ denotes the Newtonian stress component of the fluid with $\mu_{0}$, the coefficient of viscosity and $\tau_{x x}^{\prime}$ is the residual contribution terms of the Reiner-Philippoff fluid, and prime should not be considered a derivative.

Using Equation (7) in Equation (3), we get

$$
\tau_{i j}=\left(\mu_{0}+\frac{\mu_{\infty}-\mu_{0}}{1+\frac{1}{2 \tau_{0}^{2}}\left(\tau_{x x}^{02}+2 \tau_{x y}^{02}+\tau_{y y}^{02}+\ldots\right)}\right) e_{i j}
$$

Neglecting fourth and higher order terms, we get

$$
\tau_{i j}=\left[\mu_{0}+\frac{2\left(\mu_{\infty}-\mu_{0}\right)}{\tau_{x x}^{02}+2 \tau_{x y}^{02}+\tau_{y y}^{02}}\right] e_{i j}
$$

Hence, $\tau_{i j}$ is explicitly related to the gradient of the velocity by the above relation.

Let us consider $\tau_{0}$ as large, such that its exponent larger than three is negligible in the relation expressed below.

$$
\tau_{x x}=\tau_{x x}^{\infty}+\frac{\tau_{x x}^{\prime \prime}}{\tau_{0}^{2}}
$$

with the constitutive relations:

$$
\tau_{x x}^{\infty}=\mu_{\infty}\left(2 \frac{\partial \tilde{u}}{\partial x}\right), \tau_{y y}^{\infty}=\mu_{\infty}\left(2 \frac{\partial \tilde{v}}{\partial y}\right), \tau_{x y}^{\infty}=\mu_{\infty}\left(\frac{\partial \tilde{u}}{\partial y}+\frac{\partial \tilde{v}}{\partial x}\right)
$$

where $\tau_{x x}^{\infty}$ denotes the Newtonian fluid stress component with the viscosity coefficient $\mu_{\infty}$ and $\tau_{x x}^{\prime \prime}$, the residual contribution terms of the Reiner-Philippoff fluid, while the prime should not be considered a derivative sign.

Using Equation (11) in Equation (1), and neglecting higher exponent terms of $\frac{1}{\tau_{0}}$, we get 


$$
\tau_{i j}=\left[\mu_{\infty}+\frac{\left(\mu_{0}-\mu_{\infty}\right)\left(\tau_{x x}^{\infty 2}+2 \tau_{x y}^{\infty 2}+\tau_{y y}^{\infty 2}\right)}{2 \tau_{0}^{2}}\right] e_{i j}
$$

Using Equations (10) and (13) in Equations (5) and (6), we get

$$
\begin{aligned}
& \rho\left(\frac{\partial \tilde{u}}{\partial t}+\tilde{u} \frac{\partial \tilde{u}}{\partial x}+\tilde{v} \frac{\partial \tilde{u}}{\partial y}\right)=-\frac{\partial p}{\partial x}+\frac{\partial}{\partial x}\left[2 \lambda \frac{\partial \tilde{u}}{\partial x}\right]+\frac{\partial}{\partial y}\left[\lambda\left(\frac{\partial \tilde{u}}{\partial y}+\frac{\partial \tilde{v}}{\partial x}\right)\right] \\
& \rho\left(\frac{\partial \tilde{v}}{\partial t}+\tilde{u} \frac{\partial \tilde{v}}{\partial x}+\tilde{v} \frac{\partial \tilde{v}}{\partial y}\right)=-\frac{\partial p}{\partial y}+\frac{\partial}{\partial y}\left[2 \lambda \frac{\partial \tilde{v}}{\partial x}\right]+\frac{\partial}{\partial x}\left[\lambda\left(\frac{\partial \tilde{u}}{\partial y}+\frac{\partial \tilde{v}}{\partial x}\right)\right]
\end{aligned}
$$

where $\lambda$ represents the terms defined in the square brackets in Equations (10) and (13).

In the absence of pressure gradient, the boundary-layer equations are simplified to

$$
\left(\frac{\partial \tilde{u}}{\partial t}+\tilde{u} \frac{\partial \tilde{u}}{\partial x}+\tilde{v} \frac{\partial \tilde{u}}{\partial y}\right)=\frac{1}{\rho}\left[\frac{\partial}{\partial y} \lambda \frac{\partial \tilde{u}}{\partial y}\right]
$$

where

$$
\begin{gathered}
\frac{\partial \tilde{u}}{\partial y}=\frac{\tau_{i j}}{\mu_{\infty}+\frac{\left(\mu_{0}-\mu_{\infty}\right)}{1+\left(\frac{\tau_{i j}}{\tau_{s}}\right)^{2}}} \\
\frac{\partial T}{\partial t}+\tilde{u} \frac{\partial T}{\partial x}+\tilde{v} \frac{\partial T}{\partial y}-\frac{K}{\rho c_{p}} \frac{\partial}{\partial y}\left[\frac{\partial T}{\partial y}\right]=\tau\left[D_{B}\left(\frac{\partial C}{\partial y} \frac{\partial T}{\partial y}\right)+\frac{D_{T}}{T_{\infty}}\left(\frac{\partial T}{\partial y}\right)^{2}\right] \\
\frac{1}{D_{B}}\left[\frac{\partial C}{\partial t}+\tilde{u} \frac{\partial C}{\partial x}+\tilde{v} \frac{\partial C}{\partial y}\right]-\frac{\partial^{2} C}{\partial y^{2}}=\left(\frac{D_{T}}{T_{\infty} D_{B}}\right) \frac{\partial^{2} T}{\partial y^{2}}
\end{gathered}
$$

With the constraints defined at the boundaries

$$
\begin{gathered}
\tilde{u}=U_{w}, \quad \tilde{v}=0, \quad T=T_{w}, \quad C=C_{w} \quad \text { at } \quad y=0, \\
\frac{\partial \tilde{u}}{\partial x}=\frac{\partial T}{\partial x}=\frac{\partial C}{\partial x}=0, \quad \tilde{v}=\frac{d h}{d t}=0, \quad C>0, \quad \text { at } \quad y=h(t)
\end{gathered}
$$

Here, $\tilde{u}$ and $\tilde{v}$ represent the state variables, denotes the velocity components along $x$-axis and $y$-axis respectively, and $\rho$ represents the density of the fluid, local temperature by $T$, and the fluid capacitance by $C_{p}$. The ratio $\frac{\left(\rho_{c}\right)_{p}}{\left(\rho_{c}\right)_{f}}$ is the characteristic ratio of the base fluid to the nanoparticles heat capacitance; $D_{B}$ represents the direct Brownian diffusion constant; $D_{T}$ represents thermophoretic diffusion constant, $K$ is the thermal conductivity, and $T_{\infty}$ denotes the fluid temperature far away from the slit. Introducing the succeeding similarity transformations $[75,76]$

$$
\begin{array}{r}
\eta=\sqrt{\frac{\gamma}{v(1-\zeta t)}} y, \psi(x, y, t)=x \sqrt{\frac{v \gamma}{1-\zeta t}} f(\eta), \tilde{u}=\frac{\partial \psi}{\partial y}=\gamma(1-\zeta t)^{-1} f^{\prime}(\eta) \\
\tilde{v}=\frac{\partial \psi}{\partial x}=-\sqrt{\frac{\gamma v}{(1-\zeta t)}} f(\eta), \tau_{i j}=\left[x\left(\gamma(1-\zeta t)^{-1}\right)^{3}\right]^{\frac{1}{2}} g(\eta) \\
h(t)=\left[\frac{v}{\gamma(1-\zeta t)^{-1}}\right]^{\frac{1}{2}}\left(T_{w}-T_{0}\right) \theta(\eta)=T-T_{0},\left(C_{w}-C_{0}\right) \phi(\eta)=C-C_{0}
\end{array}
$$

where prime represents the change with respect to $\eta, \beta=\sqrt{\frac{\zeta}{v(1-\zeta t)}} h(t)$ represents the liquid film thickness, $\psi$ denotes the stream function, and $v=\frac{\mu}{\rho}$ is the kinematics viscosity. From the dimensionless film thickness, we can write $\frac{\mathrm{d} h}{\mathrm{~d} t}=-\frac{c \beta}{2} \sqrt{\frac{v}{\zeta(1-\zeta t)}}$, for detail see $[77,78]$. With the help of the newly introduced similarity transformations, Equations (14)-(21) are reduced to the following equations, while the continuity equation is satisfied identically. 


$$
\begin{gathered}
\frac{\mathrm{d} g}{\mathrm{~d} \eta}-\frac{1}{\epsilon}\left[S\left(\frac{\eta}{2} \frac{\mathrm{d}^{2} f}{\mathrm{~d} \eta^{2}}+\frac{\mathrm{d} f}{\mathrm{~d} \eta}\right)+\left(\frac{\mathrm{d} f}{\mathrm{~d} \eta}\right)^{2}-f \frac{\mathrm{d} f}{\mathrm{~d} \eta}\right]=0 \\
g-\epsilon \frac{\mathrm{d}^{2} f}{\mathrm{~d} \eta^{2}}\left(\frac{g^{2}+\lambda \gamma}{g^{2}+\gamma}\right)=0 \\
\frac{1}{P r}\left(\frac{\mathrm{d}^{2} \theta}{\mathrm{d} \eta^{2}}\right)+f \frac{\mathrm{d} \theta}{\mathrm{d} \eta}-2 \theta\left(\frac{\mathrm{d} f}{\mathrm{~d} \eta}\right)-\frac{S}{2}\left(3 \theta+\eta \frac{\mathrm{d} \theta}{\mathrm{d} \eta}\right)+N t\left(\frac{\mathrm{d} \theta}{\mathrm{d} \eta}\right)^{2}+N b\left(\frac{\mathrm{d} \theta}{\mathrm{d} \eta}\right)\left(\frac{\mathrm{d} \phi}{\mathrm{d} \eta}\right)=0 \\
\frac{\mathrm{d}^{2} \phi}{\mathrm{d} \eta^{2}}+S c\left[f \frac{\mathrm{d} \phi}{\mathrm{d} \eta}-2 \phi\left(\frac{\mathrm{d} f}{\mathrm{~d} \eta}\right)-\frac{S}{2}\left(3 \phi+\eta \frac{\mathrm{d} \phi}{\mathrm{d} \eta}\right)\right]+\frac{N t}{N b}\left(\frac{\mathrm{d}^{2} \theta}{\mathrm{d} \eta^{2}}\right)=0
\end{gathered}
$$

The boundary constraints of the problem are:

$$
\begin{array}{cl}
f^{\prime}(0)=1, \quad f(0)=0, \quad \theta(0)=\phi(0)=1, \quad & g(0)=0, \quad g^{\prime}(0)=1 \\
f(\beta)=\frac{S \beta}{2}, \quad f^{\prime \prime}(\beta)=0, \quad \theta^{\prime}(\beta)=\phi^{\prime}(\beta)=0, & g^{\prime \prime}(\beta)=0, \quad g(\beta)=\frac{S \beta}{2}
\end{array}
$$

The generalized physical constraints obtained are defined as: $S=\frac{\gamma}{\epsilon}$ is the non-dimensional measure of unsteadiness, $\epsilon=\sqrt{\frac{x}{v}}, \lambda=\frac{\mu_{0}}{\mu_{\infty}}$ and $\gamma=\tau_{s}^{2}\left(\frac{1-\kappa t}{c x^{\frac{1}{3}}}\right)^{3}$ are parameters of Reiner-Philippoff fluid, $\operatorname{Pr}=\frac{\rho v \mathcal{c}_{p}}{K}$ is the Prandtl number, $N t=\frac{\tau D_{w}\left(T_{w}-T_{\infty}\right)}{v T_{\infty}}$ represents thermophoresis constraint, $N b=\frac{\tau D_{B}\left(C_{w}-C_{\infty}\right)}{v}$ represents the limitation of the Brownian motion, and $S c=\frac{v}{D_{B}}$ denotes Schmidt number. All these parameters and numbers are well defined and explained briefly in literature. $C_{f x}$ and $N u_{x}$ represent the local skin-friction coefficient and local Nusselt number respectively, and are defined as:

or

$$
C_{f x}=\frac{(\tau)_{y=0}}{\frac{\rho \tilde{U}_{w}^{2}}{2}}
$$

$$
\frac{C_{f x} \sqrt{R e_{x}}}{2}=\tau_{w} \sqrt{\frac{x}{\tilde{U}_{w}^{3}}}=g(0, x)
$$

where $R e_{x}$ is known as the local Reynolds number and is defined as $R e_{x}=\frac{\tilde{U}_{w} x}{\tilde{v}}$ and $\tau_{w}$ is the value of $\tau$ on $\eta=0 . N u$ is the Nusselt number and is defined as $N u=\frac{Q_{w}}{\hat{k}\left(T_{w}-T_{0}\right)}$, while $Q_{w}$ denotes the heat flux and $Q_{w}=-\hat{k}\left(\frac{\partial T}{\partial y}\right)_{\eta=0} . S h=\frac{D_{B} J_{w}}{\hat{k}\left(T_{w}-T 0\right)}$ represents the Sherwood number in which $J_{w}$ is the mass flux, where $J_{w}=-D_{B}\left(\frac{\partial c}{\partial y}\right)_{\eta=0}$.

Sherwood number $S h$ and Nusselt number $N u$ take the dimensionless forms:

$$
N u=\Theta^{\prime}(0), \quad S h=-\Phi^{\prime}(0)
$$

\section{Solution by HAM}

The approximate solution of the Equations (23)-(26) corresponding to the Equations (27) and (28) are treated with Homotopy Analysis Method (HAM). The auxiliary parameters encircled the solution which normalize and switch to conjunction of the solutions. Let us take the initial guesses:

$$
\hat{f}_{0}(\eta)=\eta, \quad \hat{\theta}_{0}(\eta)=1, \quad \hat{\phi}_{0}(\eta)=1
$$

Let us denote the linear operators by $L_{f}, L_{\theta}$, and $L_{\phi}$ defined as:

$$
L_{f}(\hat{f})=\hat{f}^{\prime \prime \prime}, L_{\theta}(\hat{\theta})=\hat{\theta}^{\prime \prime}, L_{\phi}(\hat{\phi})=\hat{\phi}^{\prime \prime}
$$


with the property

$$
L_{f}\left(\omega_{1}+\omega_{2} \eta+\omega_{3} \eta^{2}\right)=0, L_{\theta}\left(\omega_{4}+\omega_{5} \eta\right)=0, L_{\phi}\left(\omega_{6}+\omega_{7} \eta\right)=0
$$

where $\mathcal{\omega}_{j}$ for $j \in\{1,2, \ldots, 7\}$ are the general solution coefficients. The fundamental procedure of the solution by using HAM is explained in $[72,73,76]$.

\section{Results and Discussion}

The current analysis is carried out on the thin film flow of Reiner-Philippoff fluid of boundary layer type over a time-dependent stretching plate. The aim of this subsection is to study the velocity distribution, temperature distribution, and concentration profile with physical effects of different embedding parameters, which are discussed in Figures 2-16.

Figure 2 demonstrates the thin film thickness $\beta$ during the fluid motion. In the performance of coating, thin film thickness play a key role. Physically, the thickness of the films is directly related to the velocity. Figure $2 \mathrm{~b}$ reflects a more rapid variations in $\beta$ under smaller values of $\epsilon$ and $S$ as compared to the results observed in part (a). The velocity of the fluid decreases with an increase in the thickness parameter $\beta$. It happens because for larger values $\beta$ of the fluid viscosity increases, and as a result a gradual fall can be observe in the gradient of the velocity profile.

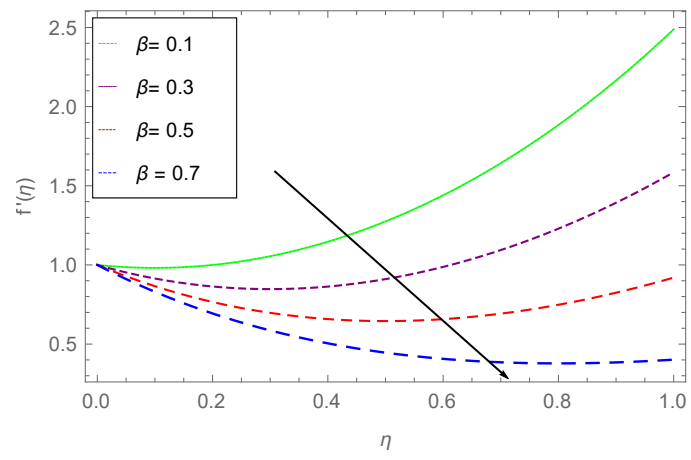

(a)

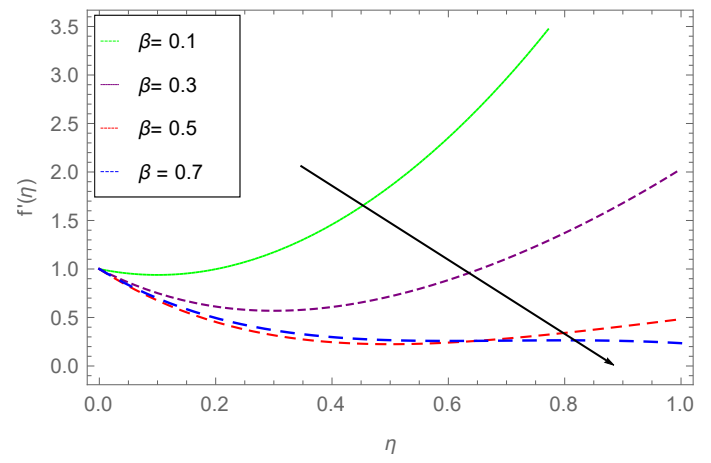

(b)

Figure 2. (a) Impact of $\beta$ on $f^{\prime}(\eta)$, when $\epsilon=0.4, S=0.2$ and (b) Impact of $\beta$ on $f^{\prime}(\eta)$, when $\epsilon=0.01, S=0.05$.

Figure 3 illustrates the effect of the stretching parameter $\epsilon$. The velocity profile shows an increase with the increasing values of $\epsilon$, because the lower plate always behaves directly to the flow fluid velocity. Physically, for $\epsilon>0$, the surface accelerating rises, $\epsilon<0$ decelerating the surface, while $\epsilon=0$ depict the random motion of the surface. Figure $3 b$ reflects the sensitivity of $\epsilon$, under smaller values of $\beta$ and $S$.

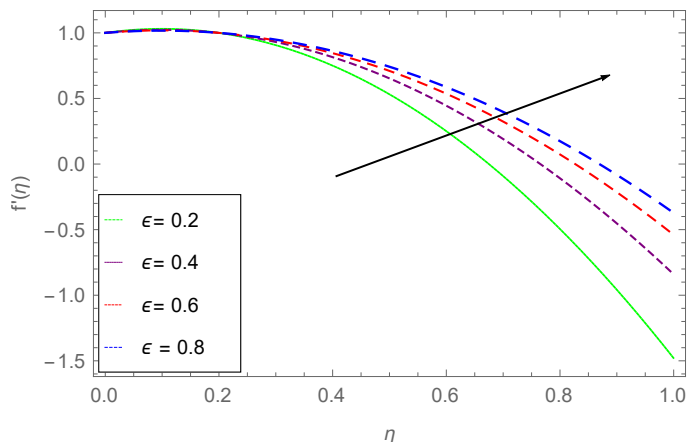

(a)

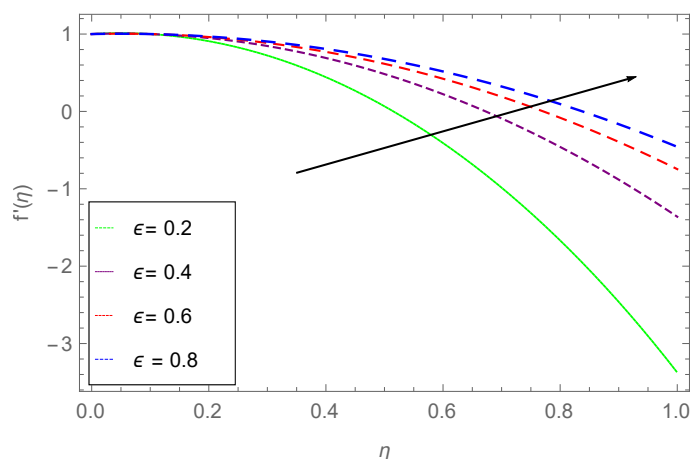

(b)

Figure 3. (a) Impact of $\epsilon$ on $f^{\prime}(\eta)$, when $\beta=0.1, S=0.2$ and (b) Impact of $\beta$ on $f^{\prime}(\eta)$, when $\beta=0.05, S=0.005$. 
Figure 4 reveals the behavior of unsteady constraint $S$ over $f^{\prime}(\eta)$ for dissimilar values of the embedded parameters. It is observed that the velocity profile $f^{\prime}(\eta)$ directly varies with unsteadiness parameter $S$. The velocity profile climes up with the increasing behavior of $S$. Furthermore, it is observed that the solution is possible only in the closed interval $[0,1]$ for $S$. Also, the increasing values of $S$ increases the motion of the nanofluid.

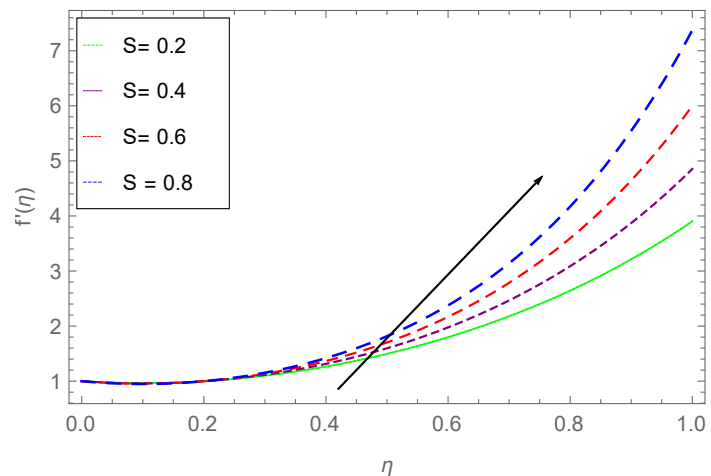

(a)

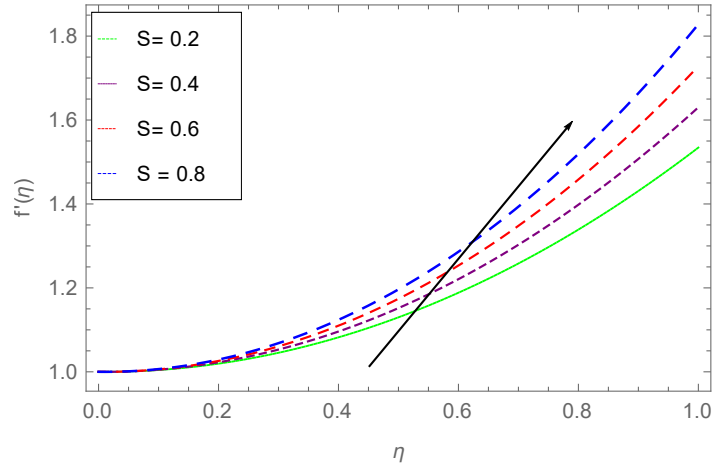

(b)

Figure 4. (a) Impact of $S$ on $f^{\prime}(\eta)$, when $\beta=0.1, \epsilon=0.2$ and (b) Impact of $\beta$ on $f^{\prime}(\eta)$, when $\beta=0.01, \epsilon=0.01$.

The impact of $\operatorname{Pr}$ on $\theta(\eta)$ is shown in Figure 5. An inverse relation has been observed between the temperature and the Prandlt number. Physically, for small values of $\mathrm{Pr}$ these fluids have larger thermal conductivity and vice versa. As a result, for larger values of $\operatorname{Pr}$ the thermal boundary layer declines.

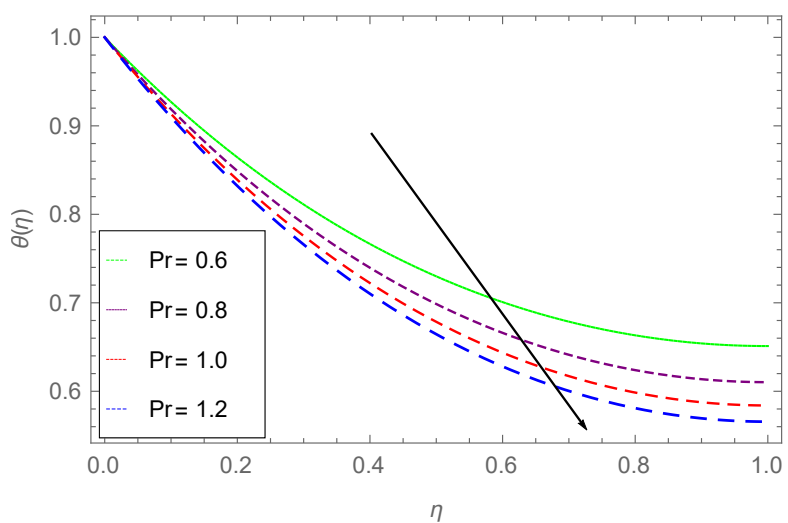

Figure 5. Impact of $\operatorname{Pr}$ on $\theta(\eta)$, when $S=0.7, \beta=1.0, \epsilon=0.4, N b=0.5, N t=0.3, S c=0.7$.

The effect of the thin film thickness $\beta$ on temperature profile for different values of the embedded parameters is shown in Figure 6. A similar effect in velocity profile is observed for $\beta$. The larger the thickness of the liquid film, the lesser the heat transfer. In other words, the flow of heat in the larger thickness film faces more more difficulty, as compared to a lesser thickness film.

Figure 7 illustrates the temperature distribution under Brownian motion parameter $\mathrm{Nb}$. In general, due to the irregular motion of the particles, this causes a collision between these particles. An increase in heat of the fluid can be seen with the ascending order of the Brownian motion parameter $\mathrm{Nb}$, consequently, free surface nanoparticle volume friction decreases.

The impact of the unsteadiness parameter $S$ on the heat profile $\theta(\eta)$ is presented in Figure 8. It is observed that $\theta(\eta)$ varies directly with $S$. An increase in $S$ increases the temperature of the fluid, which further increases the kinetic energy of the fluid, and results in increment of the liquid film motion. 


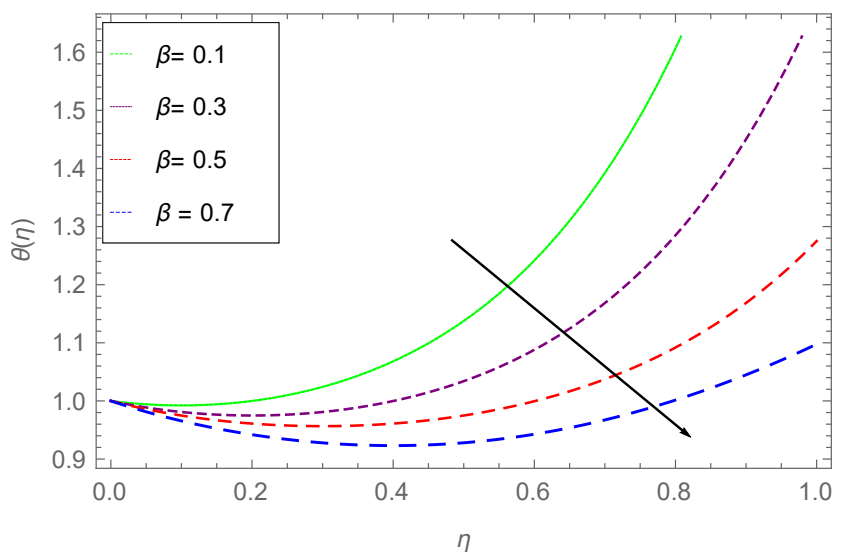

Figure 6. Impact of $\beta$ on $\theta(\eta)$, when $S=0.6, \epsilon=0.5, N b=0.5, N t=0.3, S c=0.1, P r=0.7$.

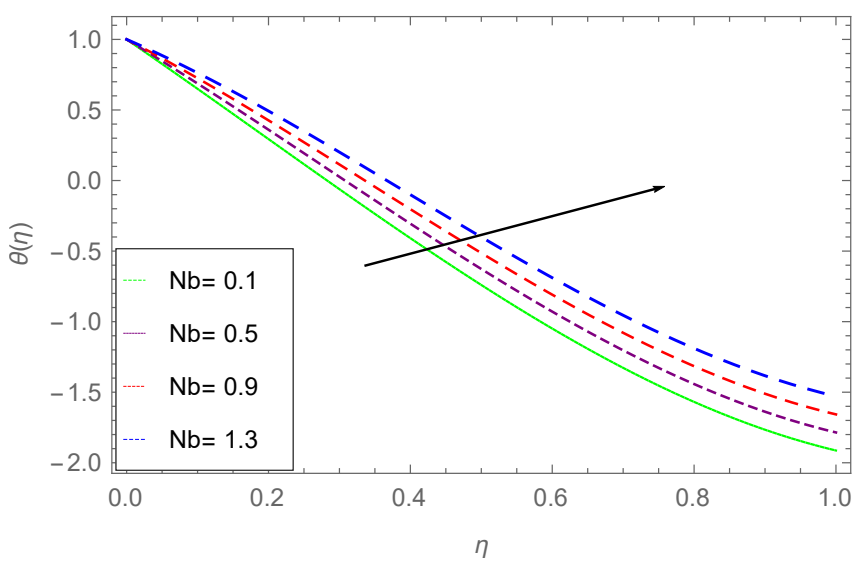

Figure 7. Impact of $N b$ on $\theta(\eta)$, when $S=0.6, \epsilon=0.5, \beta=0.4, N t=0.3, S c=0.1, P r=0.7$.

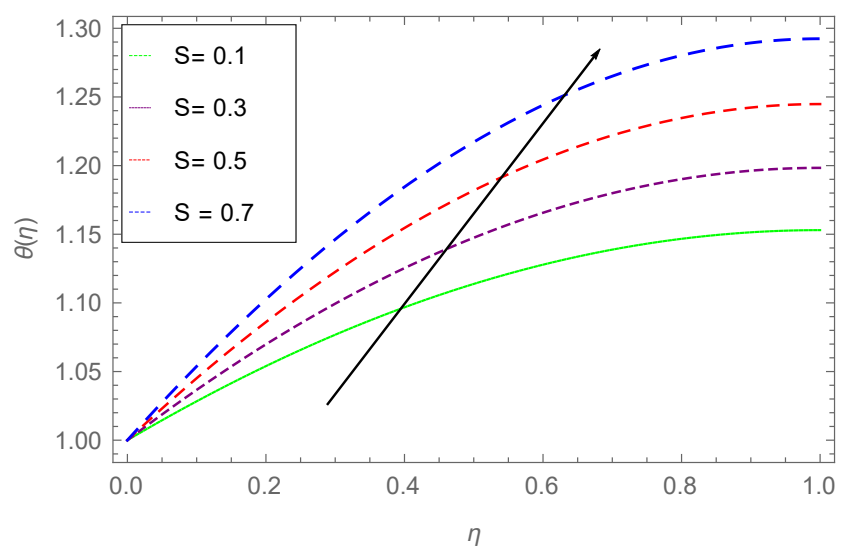

Figure 8. Impact of $S$ on $\theta(\eta)$, when $N b=0.5, \epsilon=0.5, \beta=1.0, N t=0.3, S c=0.9, \operatorname{Pr}=0.6$.

Figure 9 illustrates the effect of thermophoresis parameter $N t$ on temperature profile. The limitations thermophoresis helps in the increase of a surface temperature. The irregularity in motion (Brownian motion), causes a temperature increase due to the kinetic energy produced by nano suspended particles, which results in thermophoretic force generation. The intensity produced by this force compels the fluid to move away from the stretching sheet. As a result, larger values of $N t$ cause an increase in temperature, due to which the surface temperature also increases.

Figure 10 describes the Schmidt number effect over temperature profile. Schmidt number physically relates the boundary-layer of mass transfer to the hydrodynamics layer. Increasing rate of the viscous diffusion keeping the mass flux constant increases the Schmidt number, which as a result decreases the heat profile, as shown in the figure. 


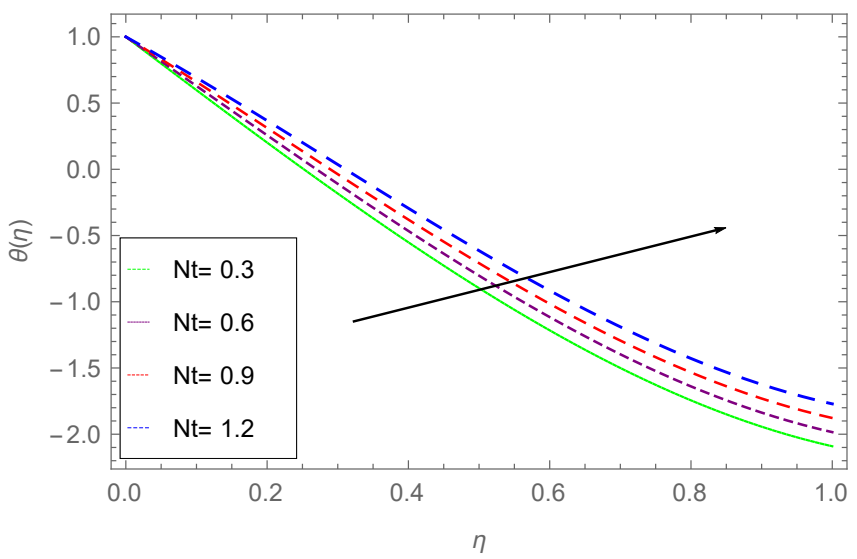

Figure 9. Impact of $N t$ on $\theta(\eta)$, when $N b=0.5, \epsilon=0.4, \beta=1.0, S=0.3, S c=0.6, \operatorname{Pr}=0.5$.

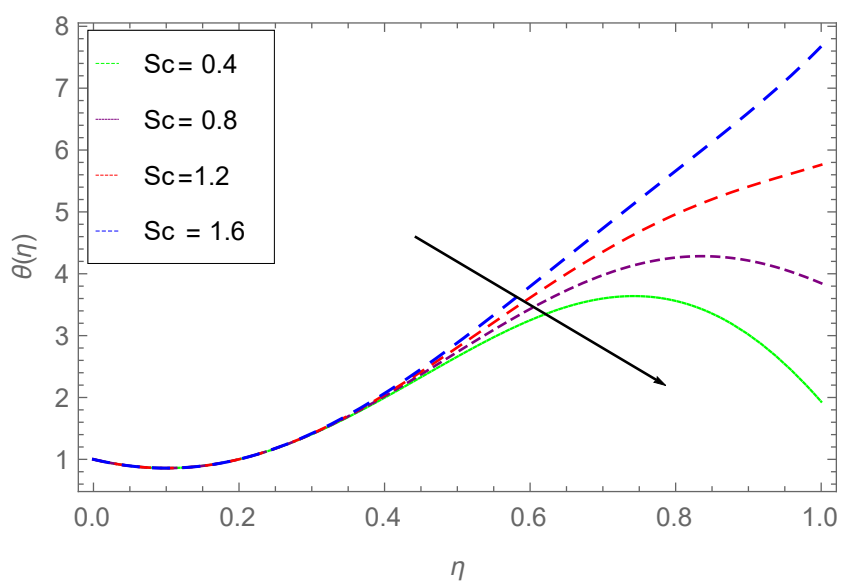

Figure 10. Impact of $S c$ on $\theta(\eta)$, when $N b=0.5, \epsilon=0.1, \beta=0.1, S=0.3, N t=0.3, P r=0.6$.

The effect of Brownian motion parameter $\mathrm{Nb}$ on $\phi(\eta)$ is shown in Figure 11. Brownian motion is the irregular motion fluid particles. At molecular level Brownian motion of micropoler nanofluid leading the thermal conductivity of nanofluids. The figure describes an inverse relation between the concentration profile and $\mathrm{Nb}$. The boundary-layer thicknesses diminishes due to an increase in $\mathrm{Nb}$, which results in reducing the concentration.

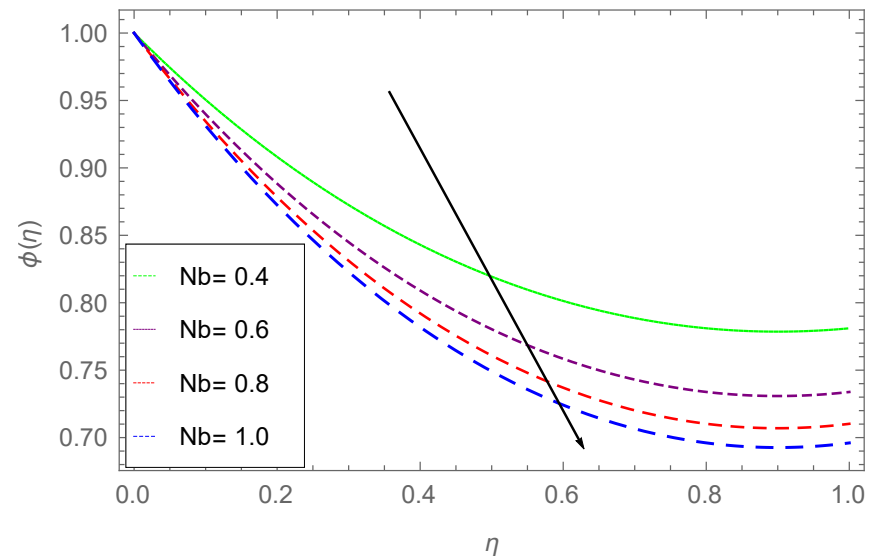

Figure 11. Impact of $N b$ on $\phi(\eta)$, when $S c=0.7, \epsilon=0.1, \beta=0.9, S=0.7, N t=0.3, P r=0.6$.

Figure 12 describes the effect of thermophoresis parameter $N t$ on concentration field. It is clear from the figure that an increase in $N t$ increases the concentration field. This is because higher values of $\mathrm{Nt}$ increase the nanofluid molecules kinetic energy, and as a result the concentration increases. 


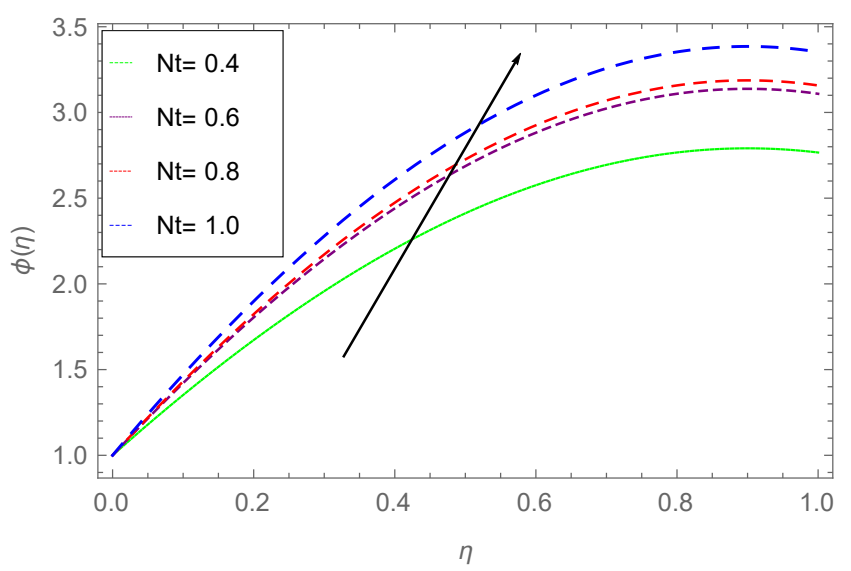

Figure 12. Impact of $N t$ on $\phi(\eta)$, when $S c=0.7, \epsilon=0.3, \beta=0.9, S=0.5, N b=0.5, \operatorname{Pr}=0.6$.

The impact of $\operatorname{Pr}$ on $\phi$ is shown in Figure 13. Larger values of the Prandtl number $\operatorname{Pr}$ cause the concentration to falls down. The information from the figure reveals that large values of $\operatorname{Pr}$ cause the concentration profile to fall down. Physically, the thermal boundary-layer vanishes with greater values of $\mathrm{Pr}$ and as a result the concentration profile falls. The same phenomenon is observed for the heat profile.

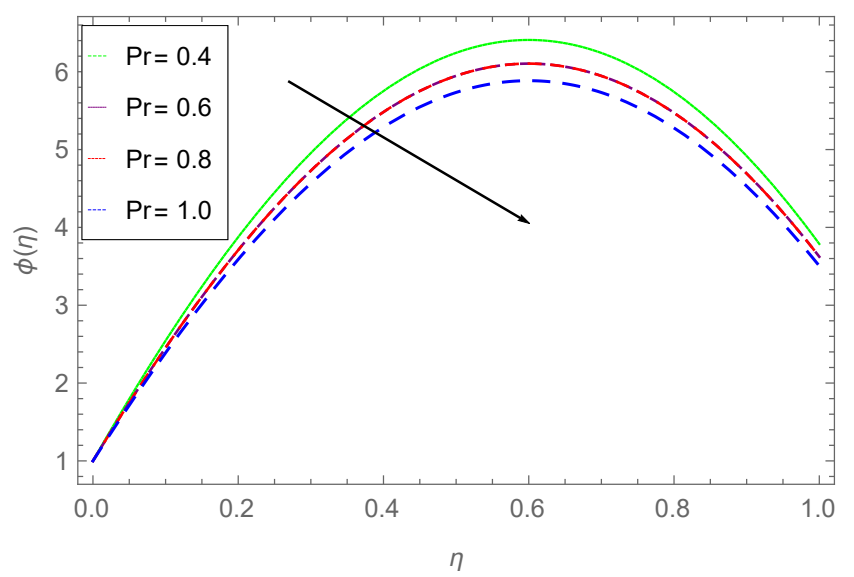

Figure 13. Impact of $\operatorname{Pr}$ on $\phi(\eta)$, when $S c=0.6, \epsilon=0.2, \beta=0.6, S=0.5, N b=0.6, N t=0.6$.

Figure 14 shows the concentration profile $\phi(\eta)$ behavior, under the effect of the unsteadiness parameter $S$. A direct relation has been observed between the unsteadiness parameter $S$ and $\phi(\eta)$ the concentration profile. Increasing the unsteadiness parameter $S$, causes an increase in the temperature to be observed, that blows the kinetic energy off the fluid, which leads to an increase in the concentration of the liquid film.

Figure 15 reveals the opposite information as discussed in the temperature distribution under different parameters. The above diagram shows that the concentration profile decreases due to an increase in Schmidt number Sc, which as a result reduces the boundary-layer thickness. This is because of the physical significance of the Schmidt number, which relates both the mass and hydrodynamic layer.

Figure 16 illustrates the effect of thin film thickness $\beta$ on $\phi(\eta)$ for the different values of the embedded parameters. It is clear that the concentration profile falls with higher values of $\beta$. The same effect has been observed for $\beta$ in the velocity distribution as well as in temperature distribution. 


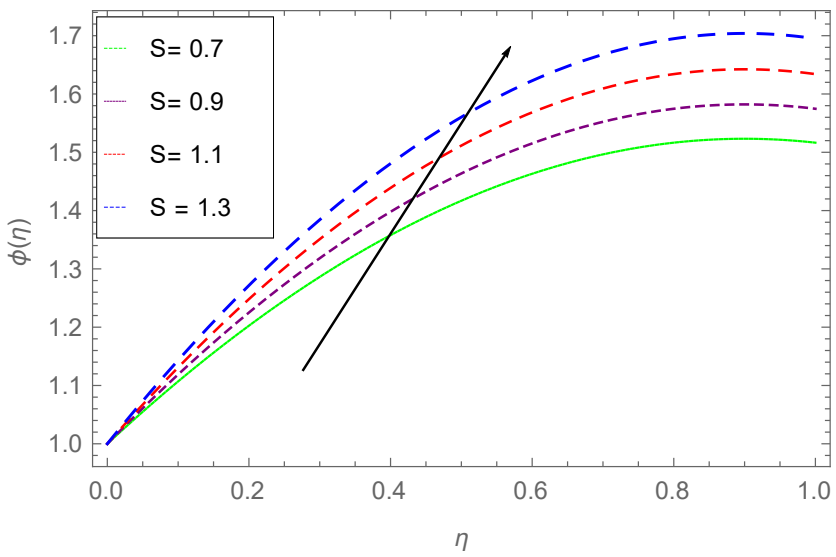

Figure 14. Impact of $S$ on $\phi(\eta)$, when $S c=0.7, \epsilon=0.8, \beta=0.9, \operatorname{Pr}=0.5, N b=0.8, N t=0.4$.

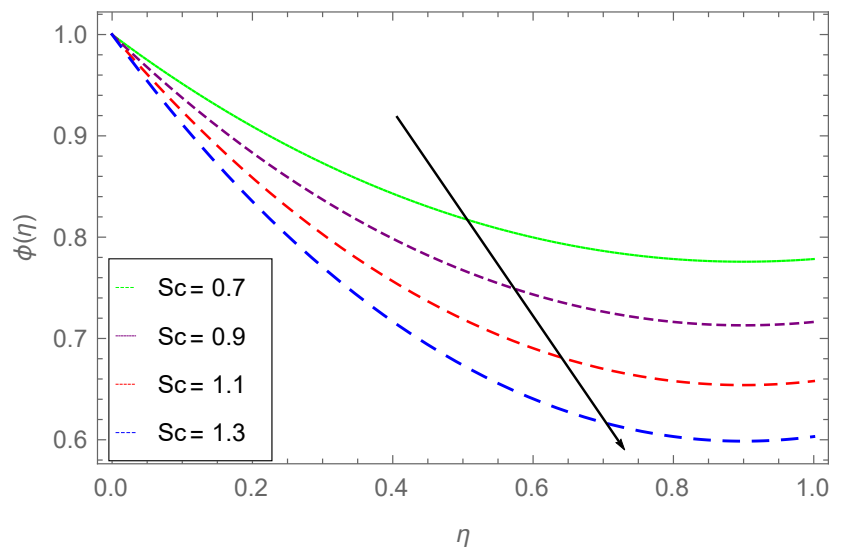

Figure 15. Impact of $S c$ on $\phi(\eta)$, when $S=0.7, \epsilon=0.8, \beta=0.9, \operatorname{Pr}=0.6, N b=0.8, N t=0.4$.

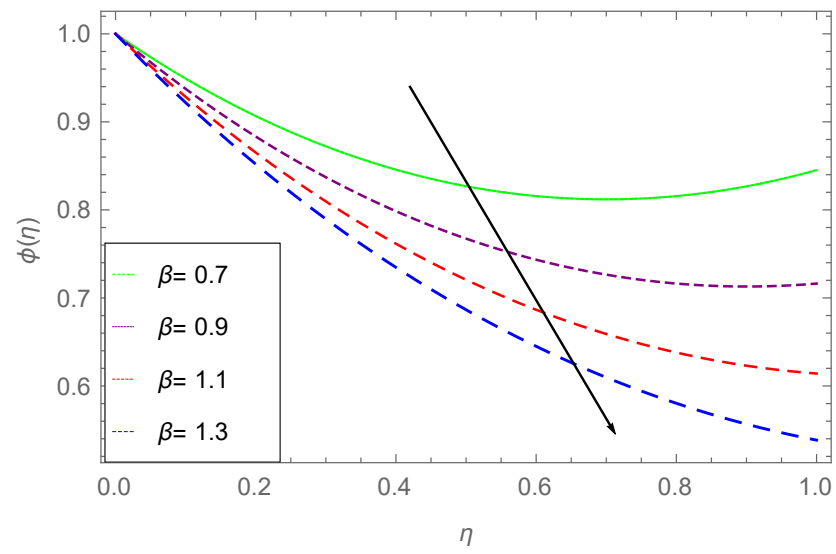

Figure 16. Impact of $\beta$ on $\phi(\eta)$, when $S=0.7, \epsilon=0.8, S c=0.9, \operatorname{Pr}=0.6, N b=0.8, N t=0.4$.

\section{Tables Discussion}

Table 1 depicts the influence of Nusselt number. The effects of $N t, S, \beta$, and $\operatorname{Pr}$ on $\Theta^{\prime}(0)$ are shown. It is clear that larger values of $N t$ and $S$ decrease $\Theta^{\prime}(0)$, while the unsteadiness parameter $S$ and thickness parameter $\beta$ increase $\Theta^{\prime}(0)$. The influence of stretching parameters $\epsilon$ and $\lambda$ of Reiner-Philippoff fluid and unsteadiness parameter $S$ on skin friction $C_{f}$ is presented in Table 2 . It is observed that the increasing values of stretching parameters of Reiner-Philippoff fluid $\epsilon$ and $\lambda$ decrease $C_{f}$, while unsteadiness parameter $S$ increases $C_{f}$. The effects of $N b, N t, P r, S c$, and $S$ on the Sherwood number $\Phi^{\prime}(0)$ are demonstrated in Table 3. It is observed that local Sherwood number values increases due to an increase in thermoporetic parameter $N t$. Increasing values of Schmidt 
number $S c$ decreases the Sherwood number, while increasing unsteady parameter and Prandtl number decreases the Sherwood number.

Table 1. Variation in Nusselt number with different values of the parameters $N t, P r, \beta$, and $S$.

\begin{tabular}{ccccc}
\hline$N t$ & $\beta$ & $S$ & $\operatorname{Pr}$ & $\Theta^{\prime}(\mathbf{0})$ \\
\hline 0.5 & 0.1 & 1.5 & 1.5 & 0.626541 \\
& & & & 0.626198 \\
& & & & 0.625771 \\
0.1 & & & & 0.625345 \\
0.5 & & & & 0.626541 \\
1.0 & & & & 0.626541 \\
1.5 & 0.1 & & & 0.626541 \\
& 0.5 & & & 2.38501 \\
& 1.0 & & & 4.78618 \\
& 1.5 & 0.1 & & 5.10531 \\
& & 0.5 & & 0.407137 \\
& & 1.0 & & 0.517063 \\
& & 1.5 & 1.5 & 0.626541 \\
& & & 3.0 & 1.08812 \\
& & & 5.0 & 1.40251 \\
& & & 7.0 & 1.56869 \\
\hline & & & &
\end{tabular}

Table 2. Variation in skin friction with different values of the parameters $\epsilon, \lambda$, and $S$.

\begin{tabular}{cccc}
\hline$\epsilon$ & $\lambda$ & $S$ & $C_{f}$ \\
\hline 0.1 & 0.9 & 0.5 & 0.17400 \\
0.6 & & & 0.42640 \\
1.0 & & & 0.54710 \\
1.8 & 0.95 & & 0.11381 \\
& 0.995 & & 0.08872 \\
& 0.9995 & & 0.07511 \\
& 0.99995 & 0.5 & 0.06632 \\
& & 1.0 & 1.18991 \\
& & 1.5 & 1.981683 \\
& & 2.0 & 2.398281
\end{tabular}

Table 3. Variation in Sherwood number with different values of the parameters $\mathrm{Nb}, \mathrm{Nt}, \mathrm{Sc}, \mathrm{S}$ and $\mathrm{Pr}$.

\begin{tabular}{|c|c|c|c|c|c|}
\hline $\mathrm{Nb}$ & $N t$ & $S c$ & $S$ & $P r$ & $\Phi^{\prime}(0)$ \\
\hline 0.1 & 0.5 & 1.5 & 1.5 & & -1.35820 \\
\hline 0.5 & & & & & -0.238811 \\
\hline 1.0 & & & & & -0.098888 \\
\hline \multirow[t]{13}{*}{1.5} & 0.1 & & & & -0.0223188 \\
\hline & 0.5 & & & & -1.35820 \\
\hline & 1.0 & & & & -2.75366 \\
\hline & 1.5 & 0.1 & & & -4.14542 \\
\hline & & 0.5 & & & -1.18991 \\
\hline & & 1.0 & & & -0.981683 \\
\hline & & 1.5 & 0.1 & & -0.398281 \\
\hline & & & 0.5 & & -0.882057 \\
\hline & & & 1.0 & & -1.12055 \\
\hline & & & 1.5 & 1.5 & -0.642239 \\
\hline & & & & 3.0 & -1.21912 \\
\hline & & & & 5.0 & -1.53875 \\
\hline & & & & 7.0 & -1.669378 \\
\hline
\end{tabular}




\section{Conclusions}

The goal of our current research is to investigate the effects of the embedded parameters on different state variables, like velocity, temperature, and the behaviour of the modeled equations under these parameters. The modeled equations are tackled with an analytical approach "homotopy analysis method" HAM. The embedded parameters and their effects are investigated and studied graphically. The motion of the suspended particles always has a great physical significance in heat transfer processes. Physically, the larger the Brownian motion parameter, the greater is the heat induction. Similar results have been observed for temperature profile with the larger values of Brownian motion. The effect of increasing values of $S c$ on boundary-layer thickness show a decrease in the thickness of the layer. The surface temperature increases with the increasing values of $P r$, while an opposite effect is observed for unsteadiness parameter $S$, i.e., large values of $S$ reduce the surface temperature. It is also observed that the temperature profile falls with large numbers of thermophoresis parameter $\mathrm{N} t$ and vice versa. It is further observed that larger values of $N b$ reduce the mass flux, where $N t$ increases the mass flux. Higher values of $S c$ reduce the flux of mass, while it increases with increasing values of $S c$. On the other hand, skin friction $C_{f}$ shows a decline in its behavior with larger values of the stretching parameters $\epsilon$ and $\lambda$, while the unsteadiness parameter $S$ increases $C_{f}$. In the solution procedure, the implemented technique convergence under the variation of physical parameters is observed numerically, which shows the reliability of our technique.

The central concluded points are as follows:

- A comparative analysis for the stretching and unsteadiness parameters for the gradient of the velocity is discussed to observe the sensitivity of these parameters.

- The temperature profile climbs up with larger values of Brownian motion parameter $\mathrm{Nb}$.

- Wth larger values of $S$, the thermal boundary layer thickness reduces.

- Higher values of $\operatorname{Pr}$ increase the surface temperature, where an opposite effect is observed for unsteady parameter $S$, i.e., large values of $S$ reduce the temperature of the surface.

- It is examined that the heat profile decreases with increasing values of thermophoresis parameter $\mathrm{N} t$, and increases with small numbers.

- The increasing values of $N b$ reduce the mass flux, where $N t$ increases the mass flux, while it rises with rising values of $S c$.

- The effect of Prandtl number Pr on concentration and temperature profile is analyzed and a similar decline is observed in both the profiles.

- The convergence of the HAM method with the variation of the physical parameters is observed, and found its convergence more rapid as compared with other techniques.

Author Contributions: Conceptualization, S.I.; Data Curation, M.A.; Investigation, A.U., Z.S. and S.I.; Methodology, A.U., Z.S. and M.A.; Resources, A.U., Z.S. and M.A.; Software, A.U. and Z.S.; Supervision, M.A. and S.I.; Visualization, E.O.A. and M.A.; Writing-Original Draft, A.U.and Z.S.; Writing-Review and Editing, E.O.A. and S.I.

Acknowledgments: This project was funded by the Deanship of Scientific Research (DSR) at King Abdulaziz University, Jeddah. The authors, therefore, gratefully acknowledge DSR for technical and financial support.

Conflicts of Interest: The authors declare no conflict of interest. 


\section{Abbreviations}

The following abbreviations and parameters with their possible dimensions stated here are used in this article:

\begin{tabular}{|c|c|}
\hline Sh & Sherhood number \\
\hline$\beta$ & Film thickness parameter \\
\hline$N u$ & Nusslet number \\
\hline$S$ & Unsteady parameter \\
\hline $\operatorname{Re}$ & Reynold number \\
\hline $\operatorname{Pr}$ & Prandtl number \\
\hline$\zeta$ & Stretching parameter \\
\hline$S c$ & Schmidth number \\
\hline$D_{B}$ & Brownian diffusion of nanofluids \\
\hline$U_{w}(x, t)$ & Stretching velocity $(\mathrm{m} / \mathrm{s})$ \\
\hline$N t$ & Thermophoretic parameter \\
\hline$C_{f}$ & Skin friction coefficient \\
\hline $\mathrm{Nb}$ & Brownian motion parameter \\
\hline$e_{i j}$ & Components of the strain rate \\
\hline$T$ & Cauchy stress tensor \\
\hline$T$ & Fluid temperature $(\mathrm{K})$ \\
\hline$\tau_{i j}$ & Extra stress tensor \\
\hline$I$ & Identity tensor \\
\hline$v$ & Kinematic viscosity $\left(\mathrm{m}^{2} / \mathrm{s}\right)$ \\
\hline$\rho$ & Density $\left(\mathrm{Kg} / \mathrm{m}^{3}\right)$ \\
\hline$\mu$ & Dynamic viscosity (mPa) \\
\hline$c_{p}$ & Specific heat $\left(\mathrm{J} \mathrm{K}^{-1} \mathrm{~g}^{-1} \mathrm{~K}^{-1}\right)$ \\
\hline$D_{T}$ & Thermophoretic diffusion of nanofluids \\
\hline$h(t)$ & Thickness of liquid \\
\hline$\kappa$ & Absorption coefficient \\
\hline$Q_{w}$ & Heat Flux $\left(\mathrm{W} / \mathrm{m}^{2}\right)$ \\
\hline$R e_{x}$ & Local Reynolds number \\
\hline$J_{w}$ & Mass flux $\left(\mathrm{K} \mathrm{g} \mathrm{s}^{-1} \mathrm{~m}^{-2}\right)$ \\
\hline$f$ & Dimensionless velocity \\
\hline$\infty$ & Condition at infinity \\
\hline 0 & Reference condition \\
\hline$\tilde{u}$ & Velocity component in $x$-direction $(\mathrm{m} / \mathrm{s})$ \\
\hline$\tilde{v}$ & Velocity component in $y$-direction $(\mathrm{m} / \mathrm{s})$ \\
\hline$x, y, z$ & Coordinates (m) \\
\hline$\eta$ & Similarity variable \\
\hline$t$ & Time (s) \\
\hline
\end{tabular}

\section{References}

1. Bird, R.B.; Armstrong, R.C.; Hassager, O. Dynamics of Polymeric Liquids. Volume 1: Fluid Mechanics; John Wiley \& Sons, Inc.: Hoboken, NJ, USA, 1987.

2. Sakiadis, B.C. Boundary-layer behavior on continuous solid surfaces: I. Boundary-layer equations for two-dimensional and axisymmetric flow. AIChE J. 1961, 7, 26-28. [CrossRef]

3. Crane, L.J. Flow past a stretching plate. J. Appl. Math. Phys. 1970, 21, 645-647. [CrossRef]

4. Siddiqui, A.M.; Ahmed, M.; Ghori, Q.K. Thin film flow of non-Newtonian fluids on a moving belt. Chaos Solitons Fractals 2007, 33, 1006-1016. [CrossRef]

5. Siddiqui, A.M.; Ashraf, A.; Azim, Q.A.; Babcock, B.S. Exact solutions for thin film flows of a PTT fluid down an inclined plane and on a vertically moving belt. Adv. Stud. Theor. Phys. 2013, 7, 65-87. [CrossRef]

6. Tawade, J.; Abel, M.S.; Metri, P.G.; Koti, A. Thin film flow and heat transfer over an unsteady stretching sheet with thermal radiation, internal heating in presence of external magnetic field. Int. J. Adv. Appl. Math. Mech. 2016, 3, 29-40. 
7. Sajid, M.; Hayat, T.; Asghar, S. Comparison between the HAM and HPM solutions of thin film flows of non-Newtonian fluids on a moving belt. Nonlinear Dyn. 2007, 50, 27-35. [CrossRef]

8. Bakier, A.Y. Thermal radiation effect on mixed convection from vertical surfaces in saturated porous media. Indian J. Pure Appl. Math. 2001, 32, 1157-1164. [CrossRef]

9. Khan, N.; Mahmood, T. The influence of slip condition on the thin film flow of a third order fluid. Int. J. Nonlinear Sci. 2012, 13, 105-116.

10. Moradi, A.; Ahmadikia, H.; Hayat, T.; Alsaedi, A. On mixed convection-Radiation interaction about an inclined plate through a porous medium. Int. J. Therm. Sci. 2013, 64, 129-136. [CrossRef]

11. Chaudhary, S.; Singh, S.; Chaudhary, S. Thermal radiation effects on MHD boundary layer flow over an exponentially stretching surface. Appl. Math. 2015, 6, 295-303. [CrossRef]

12. Eldabe, N.T.; Elsaka, A.G.; Radwan, A.E.; Eltaweel, M.A.M. Effects of chemical reaction and heat radiation on the MHD flow of visco-elastic fluid through a porous medium over a horizontal stretching flat plate. J. Am. Sci. 2010, 6, 126-135.

13. Das, K. Effects of thermophoresis and thermal radiation on MHD mixed convective heat and mass transfer flow. Afr. Mat. 2013, 24, 511-524. [CrossRef]

14. Hsiao, K.-L. Combined electrical MHD heat transfer thermal extrusion system using Maxwell fluid with radiative and viscous dissipation effects. Appl. Therm. Eng. 2017, 112, 1281-1288. [CrossRef]

15. Hayat, T.; Sajjad, R.; Muhammad, T.; Alsaedi, A.; Ellahi, R. On MHD nonlinear stretching flow of Powell-Eyring nanomaterial. Results Phys. 2017, 7, 535-543. [CrossRef]

16. Tian, X.; Li, B.; Hu, Z. Convective stagnation point flow of a MHD non-Newtonian nanofluid towards a stretching plate. Int. J. Heat Mass Transf. 2018, 127, 768-780. [CrossRef]

17. Hsiao, K.-L. Micropolar nanofluid flow with MHD and viscous dissipation effects towards a stretching sheet with multimedia feature. Int. J. Heat Mass Transf. 2017, 112, 983-990. [CrossRef]

18. Dandapat, B.S.; Gupta, A.S. Flow and heat transfer in a viscoelastic fluid over a stretching sheet. Int. J. Non-Linear Mech. 1989, 24, 215-219. [CrossRef]

19. Wang, C. Liquid film on an unsteady stretching surface. Quart. Appl. Math. 1990, 48, 601-610. [CrossRef]

20. Usha, R.; Sridharan, R. The axisymmetric motion of a liquid film on an unsteady stretching surface. J. Fluids Eng. 1995, 117, 81-85. [CrossRef]

21. Liu, I.-C.; Andersson, H.I. Heat transfer in a liquid film on an unsteady stretching sheet. Int. J. Therm. Sci. 2008, 47, 766-772. [CrossRef]

22. Aziz, R.C.; Hashim, I.; Alomari, A.K. Thin film flow and heat transfer on an unsteady stretching sheet with internal heating. Meccanica 2011, 46, 349-357. [CrossRef]

23. Andersson, H.I.; Aarseth, J.B.; Braud, N.; Dandapat, B.S. Flow of a power-law fluid film on an unsteady stretching surface. J. Non-Newton. Fluid Mech. 1996, 62, 1-8. [CrossRef]

24. Andersson, H.I.; Aarseth, J.B.; Dandapat, B.S. Heat transfer in a liquid film on an unsteady stretching surface. Int. J. Heat Mass Transf. 2000, 43, 69-74. [CrossRef]

25. Chen, C.-H. Heat transfer in a power-law fluid film over a unsteady stretching sheet. Heat Mass Transf. 2003, 39, 791-796. [CrossRef]

26. Wang, C.; Pop, I. Analysis of the flow of a power-law fluid film on an unsteady stretching surface by means of homotopy analysis method. J. Non-Newton. Fluid Mech. 2006, 138, 161-172. [CrossRef]

27. Megahed, A.M. Effect of slip velocity on Casson thin film flow and heat transfer due to unsteady stretching sheet in presence of variable heat flux and viscous dissipation. Appl. Math. Mech. 2015, 36, 1273-1284. [CrossRef]

28. Abolbashari, M.H.; Freidoonimehr, N.; Nazari, F.; Rashidi, M.M. Analytical modeling of entropy generation for Casson nano-fluid flow induced by a stretching surface. Adv. Powder Technol. 2015, 26, 542-552. [CrossRef]

29. Qasim, M.; Khan, Z.H.; Lopez, R.J.; Khan, W.A. Heat and mass transfer in nanofluid thin film over an unsteady stretching sheet using Buongiorno's model. Eur. Phys. J. Plus 2016, 131, 16. [CrossRef]

30. Ariel, P.D. Flow of a third grade fluid through a porous flat channel. Int. J. Eng. Sci. 2003, 41, 1267-1285. [CrossRef]

31. Sahoo, B.; Poncet, S. Flow and heat transfer of a third grade fluid past an exponentially stretching sheet with partial slip boundary condition. Int. J. Heat Mass Transf. 2011, 54, 5010-5019. [CrossRef]

32. Aiyesimi, Y.M.; Okedyao, G.T.; Lawal, O.W. Unsteady MHD thin film flow of a third grade fluid with heat transfer and no slip boundary condition down an Inclined plane. Int. J. Sci. Eng. Res. 2013, 4, 420. 
33. Aiyesimi, Y.M.; Okedayo, G.T.; Lawal, O.W. Effects of magnetic field on the MHD flow of a third grade fluid through inclined channel with ohmic heating. J. Appl. Comput. Math. 2014, 3, 1000153.

34. Islam, S.; Shah, R.A.; Ali, I.; Allah, N.M. Optimal homotopy asymptotic solutions of Couette and Poiseuille flows of a third grade fluid with heat transfer analysis. Int. J. Nonlinear Sci. Numer. Simul. 2010, 11, 389-400. [CrossRef]

35. Shah, R.A.; Islam, S.; Zeb, M.; Ali, I. Optimal homotopy asymptotic method for thin film flows of a third grade fluid. J. Adv. Res. Sci. Comput. 2011, 3, 1-14.

36. Makinde, O.D. Thermal criticality for a reactive gravity driven thin film flow of a third-grade fluid with adiabatic free surface down an inclined plane. Appl. Math. Mech. 2009, 30, 373-380. [CrossRef]

37. Yao, Y.; Liu, Y. Some unsteady flows of a second grade fluid over a plane wall. Nonlinear Anal. Real World Appl. 2010, 11, 4442-4450. [CrossRef]

38. Erdoğan, M.E.; Imrak, C.E. On some unsteady flows of a non-Newtonian fluid. Appl. Math. Model. 2007, 31, 170-180. [CrossRef]

39. Abdulhameed, M.; Khan, I.; Vieru, D.; Shafie, S. Exact solutions for unsteady flow of second grade fluid generated by oscillating wall with transpiration. Appl. Math. Mech. 2014, 35, 821-830. [CrossRef]

40. Nuttall, $\mathrm{H}$. The flow of a viscous incompressible fluid in an inclined uniform channel, with reference to the flow on a transporter belt. Int. J. Eng. Sci. 1966, 4, 249-276. [CrossRef]

41. He, J.-H. Variational principle for nano thin film lubrication. Int. J. Nonlinear Sci. Numer. Simul. 2003, 4, 313-314. [CrossRef]

42. He, J.-H. Variational principles for some nonlinear partial differential equations with variable coefficients. Chaos Solitons Fractals 2004, 19, 847-851. [CrossRef]

43. Hao, T.-H. Application of the Lagrange multiplier method the semi-inverse method to the search for generalized variational principle in quantum mechanics. Int. J. Nonlinear Sci. Numer. Simul. 2003, 4, 311-312. [CrossRef]

44. Liu, H.-M. Variational approach to nonlinear electrochemical system. Int. J. Nonlinear Sci. Numer. Simul. 2004, 5, 95-96. [CrossRef]

45. Liu, H.-M. Generalized variational principles for ion acoustic plasma waves by He's semi-inverse method. Chaos Solitons Fractals 2005, 23, 573-576. [CrossRef]

46. Kapitza, P.L.; Kapitza, S.P. Wave flow of thin layers of viscous liquids. Part III. Experimental research of a wave flow regime. Zhurnal Eksperimental'noi i Teoreticheskoi Fiziki 1949, 19, 105-120.

47. Yih, C.-S. Stability of liquid flow down an inclined plane. Phys. Fluids 1963, 6, 321-334. [CrossRef]

48. Krishna, M.V.G.; Lin, S.P. Nonlinear stability of a viscous film with respect to three-dimensional side-band disturbances. Phys. Fluids 1977, 20, 1039-1044. [CrossRef]

49. Andersson, H.; Dahl, E.N. Gravity-driven flow of a viscoelastic liquid film along a vertical wall. J. Phys. D Appl. Phys. 1999, 32, 1557. [CrossRef]

50. Cheng, P.-J.; Lai, H.-Y.; Chen, C.-K. Stability analysis of thin viscoelastic liquid film flowing down on a vertical wall. J. Phys. D Appl. Phys. 2000, 33, 1674. [CrossRef]

51. Chen, X.; Dai, W.; Wu, T.; Luo, W.; Yang, J.; Jiang, W.; Wang, L. Thin film thermoelectric materials: Classification, characterization, and potential for wearable applications. Coatings 2018, 8, 244. [CrossRef]

52. Yamamuro, H.; Hatsuta, N.; Wachi, M.; Takei, Y.; Takashiri, M. Combination of electrodeposition and transfer processes for flexible thin-film thermoelectric generators. Coatings 2018, 8, 22. [CrossRef]

53. Khan, Z.; Shah, R.A.; Islam, S.; Jan, H.; Jan, B.; Rasheed, H.U.; Khan, A. MHD flow and heat transfer analysis in the wire coating process using elastic-vViscous. Coatings 2017, 7, 15. [CrossRef]

54. Naghdi, S.; Rhee, K.; Hui, D.; Park, S. A review of conductive metal nanomaterials as conductive, transparent, and flexible coatings, thin films, and conductive fillers: Different deposition methods and applications. Coatings 2018, 8, 278. [CrossRef]

55. Radwan, A.B.; Abdullah, A.M.; Mohamed, A.M.A.; Al-Maadeed, M.A. New electrospun polystyrene $/ \mathrm{Al}_{2} \mathrm{O}_{3}$ nanocomposite superhydrophobic coatings; synthesis, characterization, and application. Coatings 2018, 8, 65. [CrossRef]

56. Osiac, M. The electrical and structural properties of nitrogen $\mathrm{Ge}_{1} \mathrm{Sb}_{2} \mathrm{Te}_{4}$ thin film. Coatings 2018, 8, 117. [CrossRef] 
57. Deshpande, A.P. Oscillatory shear rheology for probing nonlinear viscoelasticity of complex fluids: Large amplitude oscillatory shear. In Rheology of Complex Fluids; Krishnan, J.M., Deshpande, A.P., Sunil Kumar, P.B., Eds.; Springer: New York, NY, USA, 2010; pp. 87-110.

58. Kapur, J.; Gupta, R. Two dimensional flow of Reiner-Philippoff fluids in the inlet length of a straight channel. Appl. Sci. Res. Sect. A 1965, 14, 13-24. [CrossRef]

59. Na, T.-Y. Boundary layer flow of Reiner-Philippoff fluids. Int. J. Non-Linear Mech. 1994, 29, 871-877. [CrossRef]

60. Yam, K.S.; Harris, S.D.; Ingham, D.B.; Pop, I. Boundary-layer flow of Reiner-Philippoff fluids past a stretching wedge. Int. J. Non-Linear Mech. 2009, 44, 1056-1062. [CrossRef]

61. Patel, V.; Timol, M.G. Similarity solutions of the three dimensional boundary layer equations of a class of general non-Newtonian fluids. Int. J. Appl. Math. Mech. 2012, 8, 77-88.

62. Ahmad, A. Flow of ReinerPhilippoff based nano-fluid past a stretching sheet. J. Mol. Liq. 2016, $219,643-646$. [CrossRef]

63. Ahmad, A.; Qasim, M.; Ahmed, S. Flow of reiner-Philippoff fluid over a stretching sheet with variable thickness. J. Braz. Soc. Mech. Sci. Eng. 2017, 39, 4469-4473. [CrossRef]

64. Cole, J.D. Perturbation Methods in Applied Mathematics; Blaisdell Publ.: Walttham, MA, USA, 1968, p. 267.

65. He, J.-H. The homotopy perturbation method for nonlinear oscillators with discontinuities. Appl. Math. Comput. 2004, 151, 287-292. [CrossRef]

66. Lyapunov, A.M. The general problem of the stability of motion. Int. J. Control 1992, 55, 531-534. [CrossRef]

67. Adomian, G. Solving Frontier Problems of Physics: The Decomposition Methodkluwer; Springer: Boston, MA, USA, 1994.

68. Liao, S.-J. An explicit, totally analytic approximate solution for Blasius' viscous flow problems Int. J. Non-Linear Mech. 1999, 34, 759-778.

69. Liao, S.-J. A simple approach of enlarging convergence regions of perturbation approximations. Nonlinear Dyn. 1999, 19, 93-111. [CrossRef]

70. Liao, S.J. A uniformly valid analytic solution of two-dimensional viscous flow over a semi-infinite flat plate. J. Fluid Mech. 1999, 385, 101-128. [CrossRef]

71. Liao, S.J. The Proposed Homotopy Analysis Technique for the Solution Of Nonlinear Problems. Ph.D. Thesis, Shanghai Jiao Tong University, Shanghai, China, 1992.

72. Khan, A.S.; Nie, Y.; Shah, Z.; Dawar, A.; Khan, W.; Islam, S. Three-dimensional nanofluid flow with heat and mass transfer analysis over a linear stretching surface with convective boundary conditions. Appl. Sci. 2018, 8, 2244. [CrossRef]

73. Shah, Z.; Islam, S.; Ayaz, H.; Khan, S. Radiative heat and mass transfer analysis of micropolar nanofluid flow of casson fluid between two rotating parallel plates with effects of Hall current. J. Heat Transf. 2018, 141, 022401. [CrossRef]

74. Philippoff, W. Zur Theorie der Strukturviskosität. I. Kolloid-Zeitschrift 1935, 71, 1-16. [CrossRef]

75. Khan, N.S.; Zuhra, S.; Shah, Z.; Bonyah, E.; Khan, W.; Islam, S. Slip flow of Eyring-Powell nanoliquid film containing graphene nanoparticles. AIP Adv. 2018, 8, 115302. [CrossRef]

76. Nasir, S.; Islam, S.; Gul, T.; Shah, Z.; Khan, M.A.; Khan, W.; Khan, A.Z.; Khan, S. Three-dimensional rotating flow of MHD single wall carbon nanotubes over a stretching sheet in presence of thermal radiation. Appl. Nanosci. 2018, 8, 1361-1378. [CrossRef]

77. Shah, Z.; Islam, S.; Gul, T.; Bonyah, E.; Khan, M.A. The electrical MHD and hall current impact on micropolar nanofluid flow between rotating parallel plates. Results Phys. 2018, 9, 1201-1214. [CrossRef]

78. Jawad, M.; Shah, Z.; Islam, S.; Bonyah, E.; Khan, A.Z. Darcy-Forchheimer flow of MHD nanofluid thin film flow with Joule dissipation and Navier's partial slip. J. Phys. Commun. 2018, 2, 115014. [CrossRef]

(c) 2018 by the authors. Licensee MDPI, Basel, Switzerland. This article is an open access article distributed under the terms and conditions of the Creative Commons Attribution (CC BY) license (http:/ / creativecommons.org/licenses/by/4.0/). 